\title{
IEUBK Model to Calculate the Lead Concentration in Blood Children of the Environment which Effect by Lead Emission: Empirical Comparisons with Epidemiologic Data: Developing a Human Health Risk Model to Quantify the Risk Posed by Soil Pb
}

\author{
Ahmed Kadhim Al-Lami ${ }^{1} *$, Maitham A. Sultan ${ }^{2}$, Ali A. Al Maliki ${ }^{2}$ and Afrah A. Ajeel ${ }^{3}$ \\ ${ }^{1}$ Department of Physics, College of Science, Al-Nahrain, University, Baghdad-Iraq. \\ ${ }^{2}$ Ministry of Science and Technology, Baghdad-Iraq. \\ ${ }^{3}$ Department of Biology, College of Science, Al-Mustansiriyah University, Baghdad-Iraq. \\ * Corresponding author: alienv1969@hotmail.com
}

\begin{abstract}
For decades, human health was threaten (especially that of children) by what considered as a potential sources of lead exposure which are: lead-contaminated water, soil, and air. The proposed of the research involve developing an integrated exposure, uptake, and biokinetic (IEUBK) model as a human health risk model to predict the blood lead levels BLL in children. The data set of this project for human health risk posed by $\mathrm{Pb}$ contamination in air, water and soil were obtained from previous study achieved in 2014 which carried out on 108 school children (School children in rural areas $(n=76$ child) and School children in urban areas $(n=32$ child) matched for age. The environmental samples demonstrated that the concentration of lead for air and soil exceeded the international acceptable threshold values. However, the concentration of lead in water was below the threshold value. The BLL value from currently result of IEUBK model was above the agency's threshold of concern, $10 \mu \mathrm{g} / \mathrm{dL}$ which was documented as children's BLL lowest level of concern. This predicted values result of BLL was in agreement with actual value of BLL in blood samples of school children for the chosen study. Also, the results of this research confirmed that the high BLL could be attributed to the high lead level in both air and soil of contaminate environment.
\end{abstract}

[DOI: 10.22401/ANJS.00.1.07]

Keywords: IEUBK, Prediction of Lead Concentration, Human Health Risk, BLL, Lead hazards.

\section{Introduction}

Poisoning of lead $(\mathrm{Pb})$ is considered commonly as one of the most environmental illness of children. This element has been used in a wide variety of common products and activities that can emit lead include: industries of car batteries, paints, water pipes, leaded gasoline, and solder, crystal and ceramics, mining and smelting of lead-ores etc., [1]. The injury depending on age, socioeconomic status, the population of a given community and race, [1]. Long-term exposure to the lead may contribute to elevated blood $\mathrm{Pb}$ levels, especially in young children, who are more susceptible to elevated $\mathrm{Pb}$ concentrations in dust and soil because of their repetition of hand-to-mouth and pica behavior, [2]. The negative health effects associated with the element include the development of inhibited brain and hematological effects, like anemia [3], due to $\mathrm{Pb}$ that accumulating in the kidney, liver, teeth and bones, [4,5]. In fact, Lead
Bromide $(\mathrm{BPb})$ provides useful information about recent and historical exposures to $\mathrm{Pb}$. As a matter of fact, analysis of lead in the whole blood is the most common and accurate method of assessing lead exposure, [1]. Lead can be detected in most samples of soil, air and water, as well as in many foods and plants. Thus, all humans are exposed to levels of lead from multiple exposure pathways, including ingestion of soil and dust, ingestion of water, inhalation of lead-containing dust or soil particles in air, and food ingestion that have picking lead up from soil or water. While the BLLs of children are a good indicator of $\mathrm{Pb}$ exposure, these involve invasive sampling and are thus often difficult to obtain. So, a new technique is required to determine human health risk, as per blood sampling but which is not invasive.

Some studies suggested that a more comprehensive way of quantifying $\mathrm{Pb}$ hazards in regard to children is through the use of 
regression model to predicted $\mathrm{PbB}$ values from dust and soil, [6]. These studies used a multivariate linear regression model in order to find a slope factor relating soil lead levels to blood lead levels. The model demonstrates that raised soil lead level is accompanied with elevated blood leads in children [7], or through the use of site-specific exposure models such as the USEPA's IEUBK model[8,9]. The (IEUBK) was developed by the United States Environmental Protection Agency (USEPA) to predict human health risk posed by $\mathrm{Pb}$ contamination and elevate $\mathrm{BPb}$ levels for children under 7 years of age using the initial information about their exposure levels to lead (e.g. water, soil, air), [10,11,12].

Many studies in Iraq associated between environmental $\mathrm{Pb}$ and $\mathrm{Pb}$ exposure and health assessment. These studies found widely varying relationships between soil $\mathrm{Pb}$ concentrations and the number of people exposed to $\mathrm{Pb}$ as measured by $\mathrm{BPb}$ levels, In recent study in Baghdad was present, that lead levels in blood associated with the length of exposure to lead [13], which refers to increase the mean of BLLs for worker $20.31 \mu \mathrm{g} / \mathrm{dl}$ versus $2.91 \mu \mathrm{g} / \mathrm{dl}$ for non-worker, This study was carried out on 65 mail painters, generator worker and fuel worker in Baghdad city, the study lead to that the fuel worker had lead level in the blood more than generator worker and painters, [13].

In other study, achieved in Baghdad province at 2011 in Dorah city, found that higher $\mathrm{Pb}$ concentration in air, soils, and Plants associated with high values of $\mathrm{Pb}$ in blood, the high values of $\mathrm{Pb}$ contamination were noted in commercial parts more than agriculture part due to industrial effects (Dorah refinery, electrical power plant, private electrical generation and other private small factories), [14]. The study concluded that the higher $\mathrm{Pb}$ concentration in air, soil and Plants was related with BLLs for people in the contaminated area. Another study in southern Iraq found relationship between drinking water and concentration of $\mathrm{Pb}$ in blood of people who are living and using the marsh water, [15].

However most of these studies involve measurements for BLL in adults which not consent for IEUBK model value that specific for child between ( $0-7$ years). Due to this issue this research will depend on a valid data in other country which included $\mathrm{Pb}$ contaminated data in air, soil and drinking water, in addition $\mathrm{Pb}$ concentration in blood for children which will has more accurate result.

In this research, children's BLLs will be estimated via the IEUBK model, according to change the input parameters of the $\mathrm{Pb}$ concentration of air, water and soil. Since appropriate input data is already from literature this research does not need to involve any child participants. This contribution can supply beneficial information for policy and decision-maker to apply contamination control and risk management. In fact, integrated assessment includes two steps: (1) making a simulation for the $\mathrm{Pb}$ concentration distribution in multiple environment media model, (2) estimate lead absorbing and the BLLs.

\section{Lead exposure levels of health concern}

Through decades of medical observation and scientific research, a tremendous amount of data on the health effects of $\mathrm{Pb}$ has been obtained. By doing a comparison to most other environmental toxicants. The health effects of lead showed about quite low degree of uncertainty.

Particularly, some of these effects varies in the levels of certain blood enzymes and in symptoms of children's neurobehavioral development, may take place at blood lead levels so it is difficult to determine which degree of lead exposure, can be indicated safe for infants and children, [16]. Ryan et al. (2004) named the good sources of lead exposure such as, paints, drinking water, soil, and dust that contain lead after expulsion of leaded gasoline around lead smelters and industrial processes, [17].

An increasing number of studies report suitable signs of lead-induced neurological and/or behavioral effects in children starting at about $10 \mathrm{ug} / \mathrm{dL}$ or less, in the range of $30-40$ $\mathrm{ug} / \mathrm{dL}$ the population effects being clearer, [2]. The claims by some researchers with special interests that neurobehavioral performance is effected by lead, and the effects are longlasting and may not have a threshold value especially heme synthesis, and fetal development, [4]. Alternatively, some 
researchers and clinicians think of the low minority of the effects that occur in children at low blood lead levels, and no need to be cause for concern.

After reviewing of all the data, the EPA identified the concentration level at which effects that concern begin to take place around $10 \mu \mathrm{g} / \mathrm{dL}$ as, and has established a limit that must no more than a $5 \%$ chance of a blood lead value above $10 \mu \mathrm{g} / \mathrm{dL}$ for a child, [18]. Likewise CDCP (the Centers for Disease Control and Prevention) has decided a guideline of $10 \mu \mathrm{g} / \mathrm{dL}$ in kindery children, which is believed to stop or minimize leadassociated cognitive deficits (CDC 1991), [19].

\section{IEUBK model}

The IEUBK Model for Lead in Children was released in 2001. This model us converting estimated exposures of children lead in air, soil and dust, drinking water, and food into predicted values of blood lead concentrations, and later also risks of exceeding blood lead concentrations of concern, [18].

In order to help evaluate the risks which lead poses to young children, the EPA has developed the IEUBK Model for Lead in Children. The purpose of the model is predicting the lead level in the child blood or groups of children, under a specified set of exposure conditions, taking all sources of lead exposure into account, [19].

The IEUBK model simulates lead biokinetics in children up to age 7 years and includes a blood lead variability model and also a multipath way age-dependent exposure model, [18].

IEUBK is composed of two main parts: firstly a) the exposure section, where, the amount of lead which a child ingests or inhales is calculated using the concentration of $\mathrm{Pb}$ in each relevant ecological sectors (e.g., food, etc.), and b) information on how much of each sector picked up by a child each day. Secondly, the bio-kinetic section, which predicts the blood lead level that will result in the child from the specified exposures. This prediction is based on data regarding. In general, the model is intended to evaluate situations where exposure is on-going, and the exposure levels can be reasonably described in terms of long-term averages. In this case, the predicted blood lead level is the expected long-term average value. This long-term average value is generally considered to be suitable basis for assessing health dangers.

In real life, exposure and bio-kinetic parameters are not known for the individuals at a site, but are only available as group statistics from population studies (e.g., estimated mean soil intake rate, estimated mean gastrointestinal absorption fraction, estimated mean body weight, etc.). Because of this, the model does not seek to accurately predict the blood lead level of any one specific individual, but rather seeks to predict the typical blood lead level that would be expected in an "average" child. Blood lead levels in the entire population of all children, especially those at higher part in distribution are then estimated by generating the approximate distribution from the estimated central value. This is achieved by assuming the distribution is approximately lognormal in shape, and by applying an approximate degree of different children variability or what known as (GSD), [19].

\section{Data and techniques}

In either application of the model, three types of data are required in order to yield reliable predictions of blood lead values:

1. Lead concentrations or lead intakes from all environmental media (soil, indoor dust, air, drinking water). The data in this research were obtained according to previous study of evaluation of BLLs in a sample (primary school in Gharbia Governorate-Egypt), which achieved in 2014 and determined lead concentration in air, soil and water samples. Samples were collected from 8 locations in Gharbia Governorate. Various lead exposure sources in these locations included phosphate fertilizer industry, heavy traffic, industrial combustion plants, public power generation, commercial, residential combustion, waste incineration and metal processing as well as batteries manufacturing.

The air was collected from interior of the source point (workshop of occupationally abused children) and at different distances 
(30 m, $60 \mathrm{~m}, 90 \mathrm{~m}$ and 120) while the soil samples were collected from surface (not exceeding $5 \mathrm{~cm}$ depths). Water of children houses from 24 stations in the same 8 Locations as air was collected. Tape water was allowed to run for 20 minutes and approximately $1000 \mathrm{ml}$ of water was collected. While, the water samples were filtered through a $0.45 \mathrm{~mm}$ pore size membrane filters immediately after sampling.

2. Human exposure parameters to leadcontaining ecological aspects (intake rates of paint, drinking water. etc.). The exposure rates are usually considered to be agedependent.

3. Pharmacokinetic parameters for lead, including inhaling rates, and some blood, tissues samples. These parameters are depending on age.

Ideally, the model input parameters (especially those in group 1 and group 2, above) would be based on site-specific data as above. Other data provides recommended defaults for the parameters of the IEUBK model. The $\mathrm{Pb}$ in the blood was carried out on 108 school children (School children in rural areas ( $\mathrm{n}=76$ children) and School children in urban areas ( $\mathrm{n}=32$ children) matched for age [1]. The BLLs were used in this study to verify the BLLs obtain from model and also for correlations among (BLL) involving children and lead environment of exposure.

\section{Results and Discussion}

Lead concentrations from a variety of exposure sites were gathered. The intent of this project was not to generate accurate results for a given location but rather for demonstration and interpretation of the results. The default of model parameters was change by input the lowest and highest value of parameters of (air, water, soil). Absorption Fraction Percentages will keep constant: Soil 30\%, Dust 30\%, Drinking Water 50\%, Diet 50\%, Alternate 0\%.

The following Table (1) shows the values which were obtained and applied to the IEUBK model which exceed the standard accepted limits except those for water.
Table (1)

The lead data in air, water and soil which are applied to the IEUBK model for different areas of Gharbia Governorate, [1]

\begin{tabular}{||c|c||c||}
\hline $\begin{array}{c}\text { Air lead } \\
\text { value( } \boldsymbol{\mu g} / \mathbf{m} 3)\end{array}$ & $\begin{array}{c}\text { Environmental } \\
\text { soil value } \\
\text { (mean value of } \\
\text { soil Pb level) } \\
\text { (ppb) }\end{array}$ & $\begin{array}{c}\text { Concentration } \\
\text { of lead in } \\
\text { water in } \\
\text { different } \\
\text { houses }(\boldsymbol{\mu g} / \mathbf{l}) .\end{array}$ \\
\hline $2.72 \pm 0.23$ to & $336.59 \pm 28.53$ & \\
$6.91 \pm 0.55$ & to & $2.77 \pm 0.20$ to \\
the level of & $849.40 \pm 65.69$ & $8.57 \pm 0.5620$ \\
the National & The & The \\
Ambient Air & recommended & acceptable \\
Quality & threshold value & water lead \\
standard is & of lead in soil & limit of 15 \\
$0.15 \mu \mathrm{g} / \mathrm{m}^{3}$ & sample is 400 & $\mu \mathrm{g} / 1[21]$. \\
{$[20]$} & ppb [10] & \\
\hline
\end{tabular}

The school children in this study were chosen to be suitable with IEUBK model. $51.9 \%$ of school children were male and $48.1 \%$ were female. Concerning residence, $70.4 \%$ of them were from rural areas and $29.6 \%$ were from urban areas. The mean value of $\mathrm{Pb}$ in blood samples for school children (males and females) was $12.1 \mu \mathrm{g} / \mathrm{dl}$, with stander definition of 3.62. In contrast, the mean value of BLL in the currently IEUBK model, was $12.6 \mu \mathrm{g} / \mathrm{dl}$ (according to highest value in all media) with stander definition of 1.6.

While the mean value of BLL for lowers values of input data was 5.9 with stander definition of 1.6. Table (2) shows a comparison for the current project results (observed and predicted geometric mean blood lead) with three different communities. 
Table (2)

Comparison of Observed and Predicted Geometric Mean Blood Lead and Risk of Exceeding 10 $\mathrm{g} / \mathrm{dL}$ for four Community Blood Lead Studies, [1]

\begin{tabular}{|c|c|c|c|c|c|}
\hline \multirow[b]{2}{*}{ Study area data } & \multirow[b]{2}{*}{$\begin{array}{c}\text { Number } \\
\text { Of } \\
\text { children } \\
\text { under } \\
\text { study }\end{array}$} & \multicolumn{2}{|c|}{ Observed Blood Lead $(\mu \mathrm{g} / \mathrm{dL})$} & \multicolumn{2}{|c|}{ Model Predictions ( $\mu \mathrm{g} / \mathrm{dL})$} \\
\hline & & $\begin{array}{c}\text { Geometric } \\
\text { Means } \\
(95 \% \text { CI }) \\
\text { CI=confidence } \\
\text { interval } \\
\end{array}$ & $\begin{array}{c}\text { Percent }>10 \\
(95 \% \text { CI }) \\
\text { CI=confidence } \\
\text { interval }\end{array}$ & $\begin{array}{c}\text { Geometric Means } \\
(95 \% \text { CI }) \\
\text { CI=confidence } \\
\text { interval }\end{array}$ & $\begin{array}{c}\text { Percent }>10 \\
(95 \% \text { CI }) \\
\text { CI=confidence } \\
\text { interval }\end{array}$ \\
\hline $\begin{array}{c}\text { Galena,KA Jasper } \\
\text { Co, } \text { MI }^{\mathrm{a}} \text { lead data } \\
\text { October } 2006\end{array}$ & 111 & $\begin{array}{c}5.2 \\
(4.5-5.9)\end{array}$ & $\begin{array}{c}20 \\
(13-27)\end{array}$ & $\begin{array}{c}4.6 \\
(4.0-5.3)\end{array}$ & $\begin{array}{c}18 \\
(11-25)\end{array}$ \\
\hline $\begin{array}{c}\text { Madison Co, } \mathrm{IL}^{\mathrm{a}} \\
\text { lead data October } \\
2006\end{array}$ & 333 & $\begin{array}{c}5.9 \\
(5.5-6.4)\end{array}$ & $19(15-23)$ & $\begin{array}{c}5.9 \\
(5.4-6.3)\end{array}$ & $\begin{array}{c}23 \\
(19-28)\end{array}$ \\
\hline $\begin{array}{l}\text { Palmerton, } \mathrm{PA}^{\mathrm{b}} \\
\text { Original data from } \\
\text { Hogan } 1999 \text { [22] }\end{array}$ & 34 & $\begin{array}{c}6.8 \\
(5.6-8.2)\end{array}$ & $\begin{array}{c}29 \\
(14-44)\end{array}$ & $\begin{array}{c}7.5 \\
(6.6-8.6)\end{array}$ & $\begin{array}{c}31 \\
(16-47)\end{array}$ \\
\hline Currently study & 108 & $\begin{array}{c}3.62 \\
(3.54-3.86)\end{array}$ & $\begin{array}{c}12.1 \\
(10.19-13.94)\end{array}$ & $\begin{array}{c}5.9 \\
(4.3-6.9)\end{array}$ & $\begin{array}{c}11.7 \\
(10.7-12.6)\end{array}$ \\
\hline
\end{tabular}

Kelany et al. 2012 revealed that there was insignificant difference in BLL between urban school children and rural school children. However, the mean value of BLL in urban children was insignificantly higher than rural children. Additionally, insignificant difference in BLL between boys and girls was noticed, [1]. The Fig.(1) shows a density curve representing what blood lead level concentration is most likely to occur within the population according to lowest values (A) and highest value (B). At cut-off levels $<10$ $\mu \mathrm{g} / \mathrm{dL}$, the geometrical mean for lowest value was 5.7, while geometrical mean for highest value was (12.4).

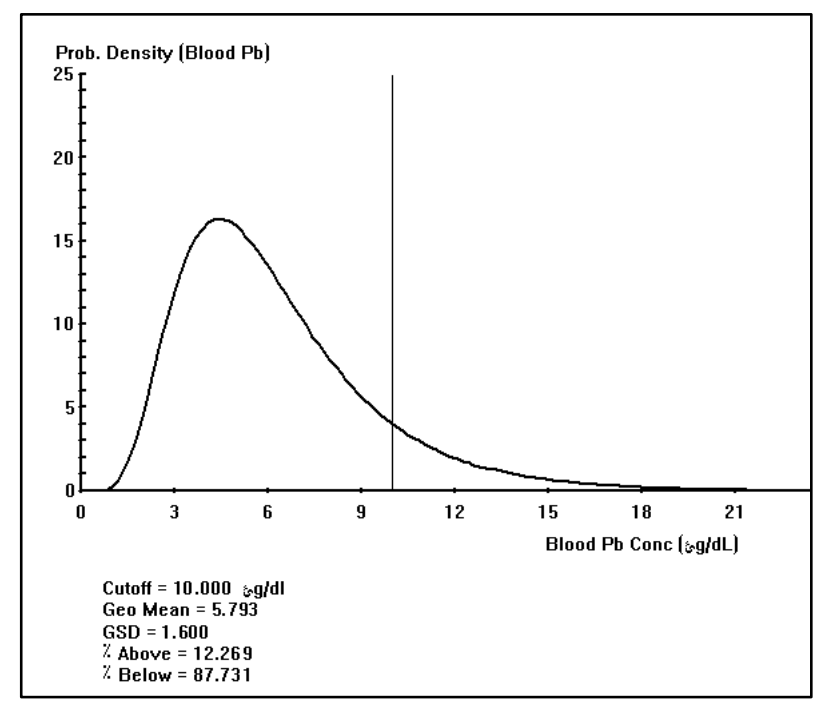

(A)

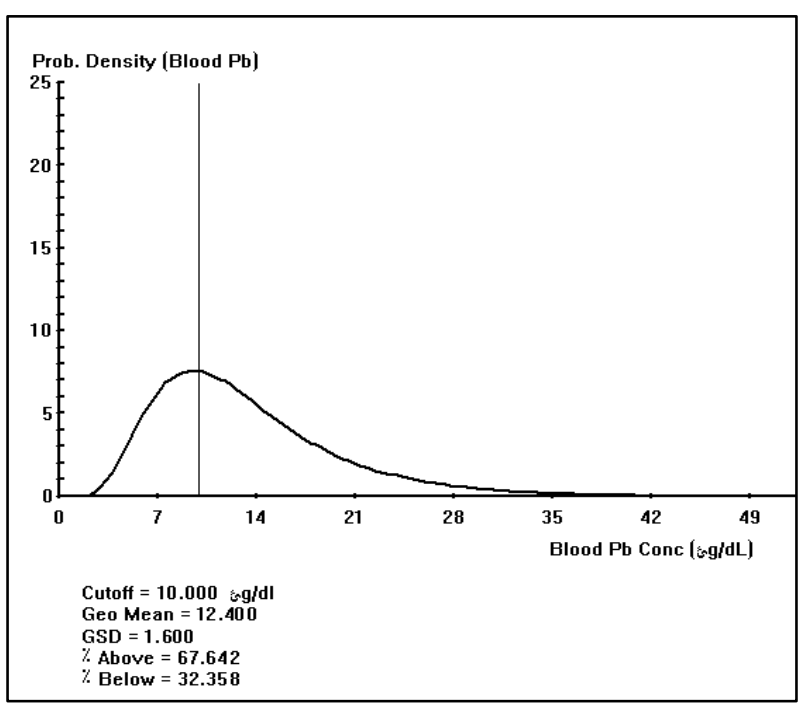

(B)

Fig.(1) Density curve for (A) highest parameter, (B) lowest parameter.

According to the curve, the majority of children exposed to the lead exposures listed above will develop blood lead levels more than $5 \mu \mathrm{g} / \mathrm{dL}$, which is above the reference level. So, interventions should be made to the child's environment to ensure their blood lead level doesn't increase in the slightest way

The distribution curve Fig.(2) demonstrates the likelihood the population that have a blood lead concentration ( $\mu \mathrm{g} / \mathrm{dL})$ at a 
given value. According to the curve Fig.(2A), there is approximately a $60 \%$ chance that the population will have blood lead levels at 5 $\mu \mathrm{g} / \mathrm{dL}$ for the given exposures listed above. That is quite a staggering number, more than half the population. While all population in the curve (B) have BLL > $10 \mu \mathrm{g} / \mathrm{dL}$, which mean no blood lead level is considered safe for a child.

Children used to be labeled with "a level of concern for harmful effects" if their blood lead

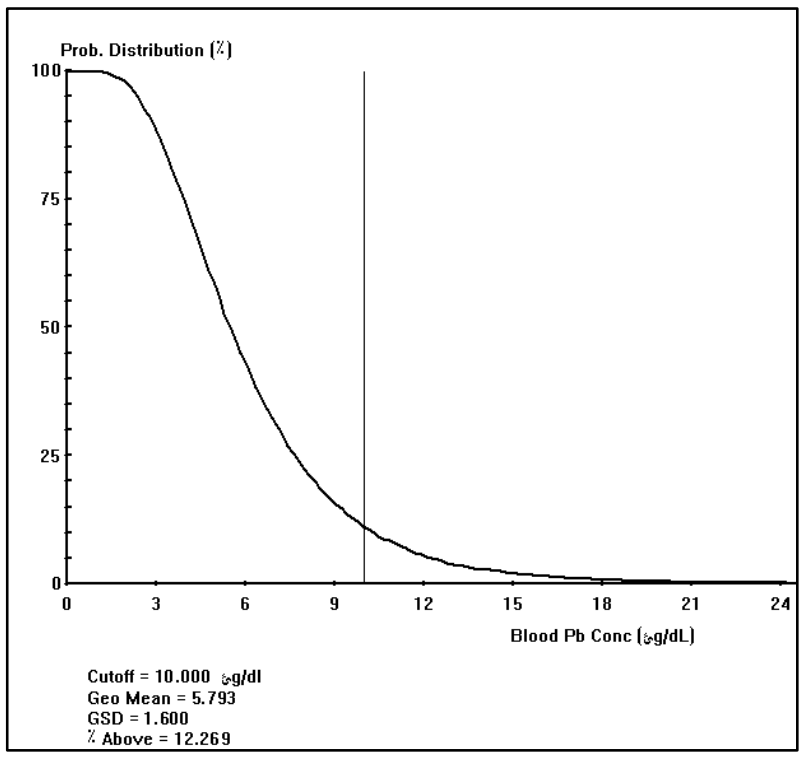

(A) levels measured $10 \mu \mathrm{g} / \mathrm{dL}$ (micrograms for deciliter of blood) or more. Since 2012, this reference level has been reduced to $5 \mu \mathrm{g} / \mathrm{dL}$, [13]. Any child with blood lead levels greater than $5 \mu \mathrm{g} / \mathrm{dL}$ is beyond the $97^{\text {th }}$ percentile and is thus considered at great risk. It is clear that these exposure sites present dangerous health effects and that some level of remediation / intervention is needed to reduce lead exposure.

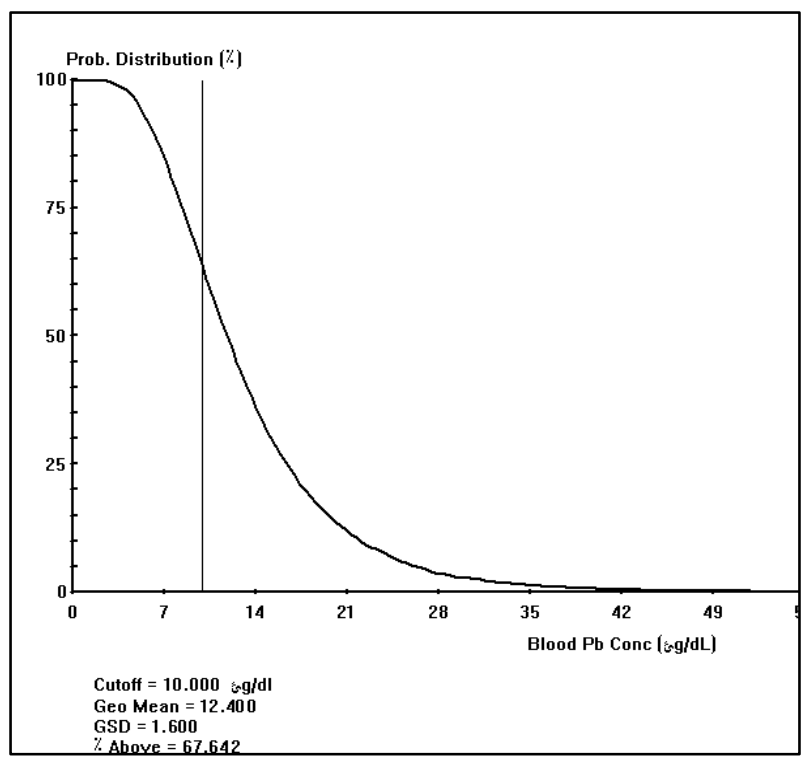

(B)

Fig.(2) Distribution curve for (A) lowest parameter with Geo- mean of 5.7, (B) highest parameter with Geo-mean of 12.4.

The current model has many advantages including inputs designed to support superfund site risk assessment, it addresses a wide range of exposure pathways. However, the model also has some disadvantage including, its inability to assess age groups above 7 years

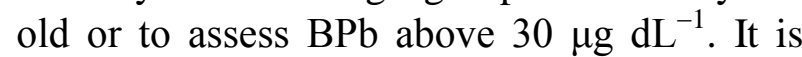
also limited to evaluating only long term exposures (exposure periods must be for at least three months), and it is unable to assess pica exposures. Furthermore, the measured $\mathrm{BPb}$ cannot match with a specific child because the model is designed to predict an average $\mathrm{BPb}$ concentration for an entire population, not individuals, [5].

\section{Conclusion}

Lead exposure is an environmental threat to the general population. It should be noted that most of the school children and their parents are not aware about lead exposure.
Study personnel field visit has been made to the study area to find out the potential sourse of $\mathrm{Pb}$ exposure. A limited number of air, water and soil samples were collected to assess the potential contribution of them to lead exposure.

The results of this research confirmed that IEUBK model had the ability to rapidly estimate BLLs for environmental health risk assessment. Also study found that $\mathrm{Pb}$ contaminated soil, and air, soil, were the main source of $\mathrm{Pb}$ exposure and contributed to lead intake among urban children.

\section{References}

[1] Kelany, R; Maddah, E; Orebey, M; and Ghaly A. "Evaluation of Blood Lead Levels and its Impact on Cognitive and Neurobehavioral Performance in a Sample of school aged Children in Gharbia Governorate (Egypt) and role of vitamin 
C'. Egyptian Journal of Medical Sciences legitimacy and Applied Toxicology, 1-19, December, 2012.

[2] Choi, J, Damm, C, O'Donovan, N, Sawyer, R,and Koshland, C \& Lucas, D., "Detection of lead in soil with excimer laser fragmentation fluorescence spectroscopy", Applied Spectroscopy, 59, 258-261, 2005.

[3] Bray, J, Rossel, R \& McBratney, A, "Diagnostic screening of urban soil contaminants using diffuse reflectance spectroscopy", Australian Journal of Soil Research, 47, 433-442, 2009.

[4] WHO, 2010, Exposure to lead: a major public health conern, World Health Organization, Geneva, Switzerland.

[5] Al Maliki A, "Reflectance spectroscopy and spatial distribution modeling of soil lead concentrations and implications for human health". Ph.D. Thesis, University of South Australia, Australia, 2015.

[6] Brian Gulson and Alan Taylor "A simple lead dust fall method predicts children's blood lead level: New evidence from Australia" Environmental Research, 159, 76-8, 2017.

[7] Lewin M, Sarasua S, Jones P., "A multivariate linear regression model for predicting children's blood lead levels based on soil lead levels: A study at four superfund sites, Environ Res. 81, 52-61, 1999.

[8] Drexler, W and Brattin, W., "An In Vitro Procedure for Estimation of Lead Relative Bioavailability: With Validation", Human and Ecological Risk Assessment, 13(2), 83401, 2007.

[9] Rasmuson, J, Rasmuson, E, Olsen, R, Hall, D, Strode, R, Larson, D \& Korchevskiy, A., "Application of a Bio-Kinetic Model (IEUBK) to Estimate the Effectiveness of Different Soil Remediation Scenarios for Lead Contamination in Shymkent, Kazakhstan", ХАБАРІІІЬСЫ, 416), 61, pp. 3-9, 2012.

[10] USEPA, 2001, Review of Adult Lead Models Evaluation of Models for Assessing Human Health Risks Associated with Lead Exposures at Non-residential areas of Superfund and Other Hazardous Waste Sites. EPA OSWER \#9285.7-46. Washington DC: Office of Solid Waste and
Emergency Response. Retrieved from http://www.epa.gov/superfund/lead/product s/adultreview.pdf.

[11] Laidlaw, M \& Taylor, M, "Potential for childhood lead poisoning in the inner cities of Australia due to exposure to lead in soil dus't", Environment Pollution, 159, 1-9, 2011

[12] Wright, J. "IEUBK Modelling for Establishing HIL A and Conducting SiteSpecific Adjustments to the Model", Environmental Risk Sciences. 1-15, 2011.

[13] Zainab N. Eyada, 2016 "Physiological effects of lead on the blood of some worker and its binding with some prepared chelating agents" Al Nahrain University, MSc thesis, Baghdad.

[14] Bushra K. Husain "Measurment of Lead Pollution on Air.Humanbeing.Soils and Plants on Dorah Regoin in Baghdad City", Al-Taqani Journal, 25(2), 1-11, 2012.

[15] Al-Rekabi, A; Al-Mashat, R. "Estimation of lead levels in human blood and marshes water in south of Iraqi" Iraqi Journal of Cancer and Medical Genetics, 6(2), 154158, 2013.

[16] Koporec, K., Sudweeks, S., Yeow, A. and Follansbee, M. "Introduction to the EPA Lead Models: Basics of Using the Integrated Exposure Uptake Biokinetic Model (IEUBK) and the Adult Lead Methodology (ALM)", Lead Modeling Training, 2007.

[17] Ryan, J; Berti, W.; Brown, S; Casteel, S; Chaney, R; Hallfrisch, J; Doolan, M., Grevatt, P, Maddaloni, M, Mosby, D., "Reducing Children's Risk from Lead Iin Soil", Environmental Science \& Technology, 38, 18A-24A, 2004.

[18] U.S. Environmental Protection Agency,. "Guidance Manual for the Integrated Exposure Uptake Biokinetic Model for Lead in Children", Office of Emergency and Remedial Response, EPA/540/R93/081, 1994.

[19] USEPA, "Sampling Manual For Ieubk Model", EPA Work Assignment No. 458HZZ, 1996.

[20] Federal Register, National Ambient Air Quality Standards for Lead 73 FR 66963, 66963-67962. Nov. 12, 2008. 
[21] Kim, E.J.; Herrera, J.E. Huggins, D.; Braam, J. and Koshowski, S., "Effect of pH on the concentrations of lead and trace contaminants in drinking water", A combined batch, pipe loop and sentinel home study. Water Research; 45, (2), 27632774, 2011.

[22] Hogan K, Marcus A, Smith R, White P. Integrated exposure uptake biokinetic model for lead in children: empirical comparisons with epidemiologic data. Environmental Health Perspectives 106 (Suppl. 6), 1557-1567, 1998.

[23] Mahmood B. "Estimation the levels of some heavy metals in the soil and vegetables irrigated with wells water in some agriculture fields at Al- Dora districtBaghdad" Iraqi Journal of Science. 57 (3B). 1918-1925, 2016.

[24] Salman A. and Eyada, Z. "Synthesis Some Pyrimidine Derivatives Act as Chelating Agents for Lead Masking”. Int. J. Curr. Microbiol. App. Sci. 5(12), 765-771, 2016. 